Revista Iberoamericana. Vol. LXIII, Núm. 180, Julio-Setiembre 1997; 449-458

\title{
CRÍTICA A LA RAZÓN HISTÓRICA: LA ASTUCIA DE LA RAZÓN DE JOSÉ PABLO FEINMANN EN LA ARGENTINA CONTEMPORÁNEA
}

\author{
POR \\ Ruta De Grandis \\ The University of British Columbia
}

If history can be dissolved into pure difference, then it suffers a massive hemorrhage of meaning; because past events only happen once, they fail to take firm root in our lives and can be expugnated from memory, having about them the ineradicable aura of pure accident.

Milan Kundera

Por lo que se ve, la realización de lo universal lleva como inseparable el interés particular de la pasión, pues de lo particular y determinado y de la negación de ello resulta lo universal. Es lo particular lo que se halla empeñado en la lucha y lo que, en parte, queda destruido. No es la Idea general la que se entrega a la lucha y oposición y se expone al peligro; ella se mantiene en la retaguardia, puesta a salvo e incólume. Debe llamarse astucia de la razón al hecho de que ella haga actuar en lugar suyo a las pasiones (...) Lo particular es, casi siempre, demasiado pequeño frente a lo universal; es así como los individuos quedan sacrificados y abandonados. La Idea paga el tributo de la existencia y de la caducidad no por sí misma, sino mediante las pasiones de los sujetos. Hegel

Marxism has penetrated so profoundly into our history that, in some way or other, at times without realizing it, we are all Marxists. Our moral judgements and categories, our ideas of the future, our opinions about the present or about justice, peace and war, everything - including our negations of Marxism - is impregnated with Marxism. It is now part of our intellectual lifeblood and our moral sensibility.

Octavio Paz

José Pablo Feinmann ${ }^{1}$ en su novela titulada La astucia de la razón (1990) enmarca todo su relato en el sistema filosófico hegeliano. Independientemente de cuán banal y adúltera sea su lectura, el narrador ofrece una visión particular de la experiencia política argentina

\footnotetext{
${ }^{1}$ Feinmann nació en Buenos Aires en 1943; es escritor y licenciado en Filosofía que ejerció la docencia en las cátedras de Filosofía de la Historia e Historia de la Filosofía Contemporánea en la Universidad de Buenos Aires. Su obra está compuesta por una treintena de ensayos filosóficos, trabajos de análisis políticos, guiones para cine y novelas. Sus novelas se están traduciendo en Italia y Francia. Sus ideas
} 
del peronismo de los años setenta, a partir de una reflexión general sobre el pensamiento filosófico de Hegel, con particular referencia al destino de la historia, a la tendencia de Hegel de considerar la filosofía como la síntesis de la totalidad de las manifestaciones del Absoluto, y a sus vinculaciones con el pensamiento político de Marx. Estas ideas hegelianas no ilustran la formación filosófico-política de un individuo en particular, sino las de una comunidad intelectual de "izquierda populista" —utilizando la denominación de Jorge Castañeda en La utopía desarmada (1993), también denominada izquierda nacional, representada en la Argentina de los años setenta por agrupaciones peronistas como Montoneros y Juventud Peronista. Según el narrador, la presencia de Hegel es fundamental para comprender dicha experiencia histórica.

La astucia de la razón cuenta la desintegración corporal y psicológica de Pablo Epstein, el protagonista, sujeto que se define históricamente embarcándose en un proceso de autorreflexión personal y colectiva por el cual obtenemos el perfil particular de la crisis de unageneración de intelectuales. Cuerpo e historia aparecen inextricablemente entrelazados. En efecto, el tratamiento del cuerpo humano y la historia fue central en la novela del proceso de reorganización nacional (1976-1983), intentando a través de esta relación decodificar para luego reconstruir las relaciones políticas y sociales, económicas y culturales preexistentes al golpe militar de 1976. En esta novelística el cuerpo no es una unidad compacta sino un cuerpo amputado por la enfermedad como correlato del cuerpo mutilado por la tortura. Recordemos Cuerpo a cuerpo de David Viñas (1979), Cuerpo a tierra de Norberto Firpo (1983), Con el trapo en la boca de Enrique Medina (1983), y El país del Minotauro de Mariano Castex (1983). ${ }^{2}$ La relación cuerpo enfermo y cuerpo amputado, historia y represión política configuró textualmente la correspondencia con un sistema de censura que pretendió imponer "el monopolio de la nominación legítima" (Bordieu, Choses Dites 161) en todos los ámbitos discursivos. El relato más representativo de este tipo de relación fue Respiración artificial, de Ricardo Piglia (1981). ${ }^{3}$ La astucia de la razón participa de ambas vertientes de esta novelística combinando una vez más el cuerpo e historia, censura y represión militar. Ahora bien, veamos particularmente qué tratamiento del cuerpo nos ofrece esta novela.

En el plano de la composición, este relato "monológico" como demostraremos más adelante, descansa sobre la base de un narrador "externo" y universal, y en un personaje principal - Pablo Epstein - en dialogismo interno que se manifiesta en el plano estilístico a través de un diálogo referido. El relato se va entretejiendo a través de las sesiones que el protagonista tiene con su psicoanalista Norman Backhauss. El narrador objetivo cuenta estas sesiones dirigiendo la atención del lector hacia un juego de doble interpretación, indicado la mayoría de las veces por el uso en cursiva de ciertos términos, que remiten explícitamente a su interpretación psicoanalítica y política. Así, repetida y obsesivamente

acerca de la historia, la realidad argentina y su literatura lo han puesto frecuentemente en el centro de intensas polémicas en la Argentina de estas últimas décadas. Feinmann es un intelectual peronista que rompió con el Partido Peronista y se negó a votar por él en las elecciones de Congreso de 1985, razón por la cual la opción peronista se vio atrofiada y dejó de representar el interés nacional (ver Hodges). En la actualidad es columnista del diario Página 12, y del semanario cultural La Maga.

${ }^{2}$ Para un estudio de este tipo de novelística, véase Vidal.

${ }^{3}$ Para un estudio de este aspecto véase, de Grandis. 
este narrador compara a Pablo tendido en el diván del psicoanalista con los "yacentes indefensos" torturados en las "parrillas" de los torturadores. Indica además que la fijación (en cursiva) de las fechas será esencial para la comprensión de la enfermedad de Pablo, señalando la correspondencia entre la intervención quirúrgica de Pablo en 1975, su posible encarcelamiento y tortura, y el golpe militar de 1976; el comienzo de su análisis el 28 de febrero de 1979 y la desintegración de Montoneros después de la virulenta contra-ofensiva del ejército argentino en ese mismo año. A partir de la intervención quirúrgica del 12 de noviembre de 1975 - como la llamaron los médicos- "la desintegración de la conciencia de Pablo" había sido progresiva, expresándose en la incapacidad para controlar sus actos de compulsión, su sintomatología repetitiva. La enfermedad de Pablo se expresa como un vaivén persistente y simultáneo entre un tumor de testículo derecho y la desintegración de su conciencia.

En este contexto psicoanalítico, Hegel aparece como el elemento fundamental de la identidad ser-existencia de Pablo, quien se expresa inmerso "en las bifurcaciones de la dialéctica hegeliana" (9). Todo el relato está imbuido del impacto de Hegel en la vida del protagonista y en la configuración de su generación. El sintagma astucia de la razón que titula la novela y que está anunciado en el epígrafe (que citamos en el encabezamiento de este trabajo) está atribuido a Hegel ("Debe llamarse astucia de la razón al hecho de que ella haga actuar en lugar suyo a las pasiones (...)" (Feinmann 13), tanto como los sucesos narrados marcaron una filosofia de la historia que se desarrollaría en la modalidad de la tragedia. Recordemos que para Hegel el aspecto esencial de la tragedia no es el sufrimiento, sino sus causas, la acción o el conflicto; el elemento de contingencia; la actividad humana se ve enfrentada con la energía de un destino impotente. Para Pablo como para Hegel, la tragedia no sólo es - como tampoco lo fue para Aristóteles - una forma literaria, sino una forma de experiencia humana profundamente filosófica, por sus implicaciones personales, éticas, políticas y religiosas, tal como lo expresan las grandes tragedias. Así, Pablo reflexionará no sólo sobre el "terror de la locura como destino, sino del dolor como destino".

La formación intelectual de Pablo como la de sus tres compañeros de estudio es hegeliana, había leído El ser y la nada de Sartre, vinculándolo a Hegel, por cuanto en Cuestiones de método Sartre abría su "invalorable y tan hegeliana", Crítica de la razón dialéctica, texto que pivoteaba sobre el concepto hegeliano de superación. Así, no era caprichoso que Sartre tomara de Hegel este concepto para exaltar la vigencia de Marx, ya que Marx había tomado ese concepto de Hegel para explicitar su pensamiento, con lo cual dijo Pablo que no muy lejos de Hegel había de rondar la frase que respondiera a la pregunta sobre el sentido final de la filosofía. Para Pablo toda la filosofía sigue rondando, o a favor o en contra de Hegel, intentando a veces superarlo, lo cual es imposible, puesto que el concepto de superación es el más hegeliano de los conceptos, y otras veces destruirlo, lo cual es también imposible puesto que la "negación sin contenidos", la negación no superadora, es también un concepto hegeliano. Pensar fuera de Hegel no sólo es imposible, sino inconcebible. De este modo, Pablo apoyándose en Sartre afirma que:

La filosofía hegeliana es la única filosofía viva de nuestro tiempo porque todas las categorías filosóficas de nuestro tiempo son las categorías filosóficas de la filosofía 
hegeliana o son deudoras de las categorías hegelianas aún aquéllas que intentan superarla o destruirlas (89).

Después de que tuvo lugar el acontecimiento que sus médicos llamaron intervención quirúrgica Pablo habría de padecer la experiencia de existir sin Hegel, no contra Hegel, no más allá, ni más acá de Hegel, sino sin Hegel, es decir, sin una continuidad de sentido, ya que la enfermedad mental le impediría concebir su locura como un momento del devenir de su existencia, como el momento dialéctico de la negación-superación. De modo que para Pablo Epstein romper con Hegel no fue una ruptura epistemológica porque Pablo no rompió con Hegel desde la razón, sino desde la locura, desde el único lugar del cual era posible romper con una filosofia que tan poderosamente había instaurado un sentido, una racionalidad, una teleología de la historia - afirma el narrador.

En cuanto a Marx, Pablo sostiene que fue un filósofo hegeliano oponiéndose así a la posición de Louis Althusser quien había intentado romper con Hegel demostrando que Marx no era la superación de Hegel, sino que entre ambos había una ruptura epistemológica. El narrador aquí introduce detalles de la historia intelectual de Pablo, que hacen a la configuración de su época. Pablo no había todavía leído a Althusser porque en 1965 no había sido aún traducido al español. François Maspero editó en 1966 Pour Marx et Lire Le Capital libros en los cuales Althusser intentaba demostrar que Marx no era la superación de Hegel, sino que entre ambos, había una ruptura epistemológica. A su vez Althusser mismo construye su ruptura epistemológica con Hegel creando así, para Pablo Epstein, una filosofía insuficiente. Si bien Althusser de su ruptura con Hegel había elaborado su filosofía, según Pablo, no obstante, nunca había podido explicar aquello que Hegel había demostrado como la continuidad sustancial de la historia. En Althusser:

[...] el pasaje de una estructura a otra, en su obstinación por destruir la continuidad sustancial, el historicismo, y la teleología hegeliana, conduce a la imposibilidad de lo diacrónico, al vértigo de la sincronía, a la calidoscopización de las estructuras, a la desestructuración (¡a él, un estructuralista!), a la esquizofrenia y a la locura, único lugar posible desde el cual era posible romper con Hegel, ya que con Hegel no se rompe desde la razón, sino desde la locura, tal como lo hizo Althusser (90-91).

Por analogía, Pablo Epstein, como Althusser, se había transformado también en un filósofo loco.

Marx, insiste Pablo Epstein, fue un filósofo hegeliano toda su vida, desde su tesis doctoral sobre las diferencias entre Demócrito y Epicuro, escrita en Jena en 1841, hasta el prefacio a la edición rusa del Manifiesto comunista escrito en Londres con Engels, en enero de 1882. Las cimas del pensamiento a las cuales Marx llegó fueron posibles porque Marx lo hizo desde la filosofía hegeliana - afirma Pablo. Por eso, repite Pablo una y otra vez a su psicoanalista, que todo Marx es una frase anterior de Hegel, o que todo Marx está contenido en Hegel y, refutar los supuestos de Hegel implica refutar los de Marx. En esta autorreflexión psicoanalítica y filosófica en la que se ha embarcado Pablo, el desafío que tanto él como sus tres compañeros de estudios habían tenido que enfrentar había sido el de encontrar la frase que resumiera el sentido final de la filosofía. Pablo Epstein busca este sentido en la introducción a La crítica de la filosofia del derecho de Hegel que el joven Marx 
escribió a fines de 1843, cuando apenas tenía 25 años, un texto transparentemente hegeliano, en donde Marx se pregunta por el sentido final de la filosofía, tramando en torno al concepto de crítica. Para Pablo, Marx fue un filósofo constituido por la crítica a Hegel, cuya crítica al sistema capitalista la realizó sin desligarse del sistema hegeliano. En este constante discurrir entre Hegel y Marx, Pablo reflexiona sobre sí mismo, analógicamente a partir de Marx, particularmente al considerar la crítica no como un fin en sí mismo, sino únicamente como un medio, cuyo pathos es la indagación, y cuya labor, la denuncia. Ahora bien, ¿cuál es la denuncia que desde el pathos de la indagación debe realizar la filosofía? se pregunta Pablo Epstein y, su respuesta es: la denuncia de la opresión, incluyendo a ésta en el espacio de la filosofía. La conciencia como esencia de la filosofía reaparecerá en Pablo Epstein cuando después del "derrumbe" (de la revolución peronista), podrá pensar su neurosis:

[...] puesto que si la conciencia en Marx hacía más opresiva la opresión, más ignominiosa la ignominia, ... la conciencia de la neurosis hacía más intolerable la neurosis que despertaba el sufrimiento (100-101).

Neurosis que, como el razonamiento sobre el joven Marx en tanto filósofo hegeliano, gira en torno a la insoslayable unión entre la filosofía, es decir, el espíritu y el sujeto, es decir, la materia, la sustancia, el proletariado.

La Introducción a la crítica de la filosofía del derecho de Hegel conduce a La fenomenología del espiritu, en cuyo prefacio está la frase que según Pablo resume el sentido final de la filosofía: aprehender y expresar lo verdadero, no como sustancia, sino precisamente también como sujeto ["appréhender et exprimer le vrai, non comme substance, mais précisement aussi comme sujet" (107)]. Frase contenida en la Tesis sobre Feuerbach, porque cuando Hegel identifica al sujeto con la sustancia, Pablo se pregunta y nos pregunta “¿no creen ustedes?” que Marx de ahí deduce su “horizonte conceptual desde el que formulará su célebre y épica tesis" acerca de que "la teoría se transforma en fuerza material cuando se apodera de las masas" (108-109). No se trata de que el sujeto se apodere de la sustancia, sino que el sujeto deviene sustancia. Pablo Epstein revela que Hegel al articular el pensamiento con la historia introdujo una racionalidad, un sentido, una teleología en la historia instaurando kantianamente una historia humana hecha y pensada por los hombres, y lo hizo postulando que el sujeto-objeto puede aprehender la historia haciendo de lo histórico también un sujeto, es decir, la creación de un sujeto. Pero esta "explicación" Pablo la extrajo de El joven Hegel y los problemas de la sociedad capitalista de Luckacs, que ha sido esencial en su formación hegeliana y más aún, su formación filosófica. Evidentemente, este libro será muy importante para Pablo porque lo "ha hecho tan suyo, tan subrayado, estudiado, anotado en sus márgenes, que ha dejado de ser de Luckacs" y ha pasado a ser de Pablo. Años más tarde cuando ya se había declarado su locura, no reconocería ni quién, ni cuándo, ni cómo, ni por qué, y esas anotaciones aparecerían incomprensibles.

En 1965, Pablo había escrito un trabajo sobre el concepto de naturaleza en la filosofía de Hegel, que le sería útil para pensar su neurosis. En ese entonces cuando ni él, ni los tres jóvenes estudiantes de filosofía padecían de los desórdenes del espiritu, se habían reunido en la ciudad balnearia de Mar del Plata, allá por 1965 para hablar sobre el sentido final de 
sus vidas. Pablo pensaba que lo que mantenía en orden sus conciencias era la profunda creencia de que participaban de un orden inmanente de los hechos históricos, que según Hegel ordenaba sus conciencias. Este supuesto metafisico, este sentido de la historia entregaba un sentido a sus vidas, alejándolos de los desórdenes del espíritu. Años más tarde Pablo pensaría que el verdadero sentido del saber filosófico consistía en pensar la historia, la sociedad, la política, la vida y la muerte, al margen de todo supuesto ontológico, de todo supuesto metafísico, de toda teleología, digamos de toda filosofía de la historia. Si las filosofías de la historia habían reemplazado a los viejos dioses, Pablo se pregunta "¿qué nuevos dioses reemplazarán a las filosofias de la historia?" Y la respuesta está en un texto clave: Tesis sobre Feuerbach en el que Marx le quita la inocencia a la filosofía al comprometerla con la realidad "en el modo de la transformación". La frase "los filósofos no han hecho más que interpretar de diversos modos el mundo, pero de lo que se trata es de transformarlo" restituye el sentido final de la filosofía.

En este discurrir de lecturas filosóficas y políticas del marxismo europeo, Pablo Epstein, en el desesperado intento por encontrarle un sentido a la historia, llega al personaje demorado, "el más filósofo de los personajes de esta narración", anunciado varias veces a lo largo del relato: John William Cooke, curioso nombre "imperialista" de este héroe de la revolución nacional de origen irlandés. Pablo lo había conocido en Córdoba una noche de 1964 ante los estudiantes en la sede estudiantil (porque el aula magna de la universidad le había sido prohibida) cuando Cooke dirigiéndose a los "compañeros" les había hablado a estudiantes y obreros o dirigentes combativos sobre el reciente y frustrado regreso del general Perón a la Patria, frustrado en el aeropuerto de El Galeao por la dictadura brasileña a pedido del gobierno de Dr. Illia que gobernaba a base de la proscripción política y electoral del peronismo. Para Cooke, la antinomia peronismo-antiperonismo era la expresión de la lucha de clases en Argentina, y había que luchar hasta con sangre si era necesario, exaltando así la praxis de la militancia. En la serie de relaciones entre el marxismo y el sistema filosófico hegeliano Cooke había venido a agregar otro matiz interpretativo al sentido final de la filosofia condensado en la frase "El peronismo es el hecho maldito de país burgués", que para la izquierda peronista del momento implicaba reconocer el liderazgo de Perón pero rechazar su conducción estratégica.

Después de este recorrido y volviendo una vez más a Hegel, Pablo se pregunta por los espacios que Hegel había dejado en blanco, señalando la inexistencia de América en el pensamiento de Hegel, en particular en sus Lecciones de filosofia de la historia universal, y en el párrafo titulado El Nuevo Mundo:

América, e infinitamente más aún: Latinoamérica, no existe en la filosofía de Hegel. O existe como esencia. $\mathrm{O}$ como carencia. $\mathrm{O}$ como eco. $\mathrm{O}$ como reflejo de una vitalidad ajena (173).

Según Pablo, aquí el filosofo ahogaría la dialéctica en la política del Estado, pues la cultura americana (refiriéndose a las precolombinas de México y Perú) tenía un carácter natural que en los labios de un europeo significa ajeno al espíritu, deduciéndose que un europeo jamás es un natural (ya que los europeos hablan el lenguaje del colonizador y éstos jamás se dicen natural de Londres, o de Berlín, sino ciudadano de) pero sí se es natural de 
la India, de África, o de América Latina, por lo cual Hegel confirmó que América pertenecía a ese ámbito de lo natural. Entonces, para Pablo esas culturas - la mexicana y peruana por ejemplo- estaban destinadas a morir no bien el Espíritu se les aproximara, por eso Hernán Cortés era el Espíritu que al entrar en contacto con las culturas naturales de América no había podido sino conducirlas a la muerte, siendo una destrucción históricamente progresiva ya que implicaba un desarrollo del Espíritu. Aunque Hegel no nombra a Cortés, éste está implícito, agrega Pablo. De modo que América era débil tanto física como espiritualmente y estaba fuera del terreno de la historia universal. Todo cuanto ocurriría en América era expresión de una vitalidad ajena, que venía de Europa. Así el continente americano no había tenido cabida en la filosofía de Hegel, y como Hegel se había posicionado en el lenguaje del colonizador y no en el del colonizado, según Pablo, para existir libremente habría que existir sin Hegel. Así llega al teorema latinoamericano en torno a Hegel y al marxismo; este "asado filosófico" (otra recreación de la payada intelectual entre Borges y Groussac en Respiración artificial de Ricardo Piglia, o del asado antropofágico en El entenado de Juan José Saer), había sido el clima espiritual de la época desde el cual pensar la historia y la política. Así cuando Hegel dice lo verdadero es el todo está diciendo lo verdadero es la historia como autodespliegue del Espíritu. Después de la Revolución Francesa Hegel había tenido que adueñarse de la historia desde el pensar, desde la conciencia, desde el sujeto, haciendo de la Historia un sujeto historizado e historia subjetivizada, consciente y racional. De ahí su fracesita: todo lo racional es real y todo lo real es racional que supone los conceptos de necesidad - el desarrollo histórico no es contingente sino necesario, de negatividad: toda formación histórica es contradictoria, lleva en sí el germen de su autodestrucción, dando surgimiento a otra formación que contiene la anterior-y de superación:

toda forma histórica es necesaria pero a la vez transitoria, genera su propia negación, que será su momento lógico-reflexivo, el momento del entendimiento kantiano, que aísla las determinaciones, pero es incapaz de conducirlas al ámbito de la racionalidad dialéctica, de la razón totalizadora [...] (224).

La frase de Hegel todo lo racional es real y todo lo real es racional se justificaría solamente por medio de la exposición del sistema. Para Pablo los supuestos del pensar de Hegel:

[...] son aquellas categorías que, cuando estén fundamentadas dentro del sistema, uno detecta, advierte y finalmente, digamos, denuncia que $\sin$ esas categorías ese pensar se derrumba (228).

Volviendo al teorema latinoamericano que cerrará la reflexión sobre Hegel, Pablo vuelve a Marx, pues es en Marx donde hay zonas ciegas, de no fundamentación, que son las categorías hegelianas que Marx incorpora "a-críticamente" de las cuales le bastará con mencionar dos; "superacióny teleología". Dentro de este teorema, Marx se latinoamericaniza mediante un encuentro entre Marx y el caudillo montonero catamarqueño Felipe Varela el 10 de abril de 1867, en Pozo de Vargas en la provincia de La Rioja. En este encuentro, el creador del socialismo científico y un miembro del caudillismo americano del siglo XIX 
discuten sobre la finalidad de la Historia y sus leyes. Este Marx barbado e "inesperado", con una abundante cabellera que nos recuerda la del caudillo Facundo Quiroga, trata de explicar que no serían los gauchos los que vengarían "toda injusticia y crueldad", sino los obreros. Para Marx aunque los caudillos derroten los sistemas de gobiernos europeizantes nada cambiaría en el futuro porque los caudillos mismos se transformarían en opresores. Este encuentro situado en los albores de la nación argentina, presenta un Marx más preocupado en exhibir su humanismo que "sus convicciones sobre las necesidades dialécticas de la historia" (249), un Marx, alejado de las inclemencias históricas de la dialéctica, menos, en consecuencia, hegeliano, y más atento a las especificidades de los pueblos periféricos. "Un Marx [...] que fue capaz de entregar un consejo que no aceptaron los marxistas argentinos: no transformar El Capital en una filosofia de la historia" (249). Con esto, el relato llega a la etapa culminante del teorema latinoamericano; el espacio políticoideológico que explica dicho teorema implica una ruptura con el espacio políticoideológico desde el que Marx pensó:

Yo, militante de la causa nacional y popular latinoamericana, pienso desde un espacio ontológico diferente al de Marx. Yo pienso como latinoamericano. Y América Latina es un nuevo rostro del ser, un nuevo surgimiento ontológico [...] (249).

Pablo afirma que Marx ignoró el surgimiento del Tercer Mundo como fuerza histórica y política destinada a cuestionar el orden burgués en el siglo XX, y que los intelectuales argentinos, como nuestro protagonista, entendieron que transformar la historia era posible desde el peronismo, pero transformándolo como había sido la consigna de Cooke.

Así concluye el recorrido irónico y agónico de La austucia de la razón, "alucinación dispersa en agonía" - diría Beatriz Sarlo (1-8) - en donde las pasiones político-filosóficas provocan la impotencia del protagonista masculino, corporalmente corroborada en la amputación del testículo derecho de Pablo Epstein. Experiencia de extrema impotencia que toma una vez más la metáfora repetida de los poetas modernistas ingleses, T.S. Eliot en particular, y su mitológico Fisher King aludido en "The Waste Land". Pero es aún algo más que una metáfora de la modernidad poética. Testis, palabra anatómica que designa testículo, órgano reproductivo masculino, diminutivo del latín testiculus cuya raíz testis significa testigo, siendo el órgano evidencia de virilidad. La conexión etimológica entre testigo y testículo nos lleva al espacio de la esfera pública, señalan Nancy Fraser y Lucie White. Si en la antigüedad la posesión de penis era el requisito para hablar en público, en La astucia de la razón la amputación de una parte del aparato viril testimonia la pérdida de ese espacio. Así, esta novela del cuerpo puede leerse también como un relato testimonial de exclusión y desmembramiento de la instancia pública, que no hace sino reforzar esa mitología de la exclusión que en el siglo XIX fabricó la nación, en las palabras de Nicolás Shumway.

Ahora bien, ¿no parece irónico y anacrónico traer a colación esta novela publicada en 1990 al debate de este segundo lustro de los años noventa, marcado por la caída de los imaginarios de izquierda, la globalización económica bajo el signo ideológico del neoliberalismo, y la expansión de las democracias liberales a las emergentes naciones del antiguo bloque del este europeo, y de América Latina, como sucedáneas de los previos regímenes militares, y a los países del sur de África bajo dominación racial? Quisiera 
concluir el recorrido de esta novela en la que se reflexiona sobre la historia como contexto y finalidad desde Hegel dentro de los interrogantes actuales sobre el estado actual de los intelectuales y las crisis de las izquierdas en América Latina. Si como sugiere Jorge Castañeda, parte de las crisis de la izquierda en América Latina se debe a las acciones de los movimientos armados, siendo Montoneros un ejemplo paradigmático, La astucia de la razón no parece dialogizar dicho movimiento y sus ramas políticas. Por el contrario, la novela está saturada de los ideologemas articuladores de la cosmovisión política de la época, sin un cuestionamiento de los mismos. La astucia de la razón como dispositivo para repensar la experiencia política del peronismo setentista se mira a sí mismo desde sí mismo, y llega a la conclusión de que la opción populista del marxismo argentino fue una contingencia inevitable. De ahí su monologismo, su cuestionamiento desde dentro y no desde fuera de su propia secuencia cronológica, no hay una secuencia anterior y otra posterior desde la cual leerse. Monologismo que afecta también las relaciones genéricas del relato, ya que se construye como exclusivamente "masculina". Acaso no podríamos decir que se trata de una novela de duelo, tal como Carlos Altamirano califica a Cazadores de utopías, estrenada en marzo de 1996, "sobre las vísperas de aquel 24 de marzo de veinte años atrás"; película hecha por ex-Montoneros para ex-Montoneros que está regida por la idea de "que todo puede ser comprendido desde el interior de esa misma experiencia, interpretada de acuerdo a los relatos de siempre" (Altamirano 1-9). Recurrencia de los espectros del marxismo, "fantasmas del pasado," como titula Raúl Beceyro su análisis de Cazadores de utopías, que puede aplicarse también a la novela de Feinmann (Beceyro 10-12). Si las experiencias a las que aluden estos artefactos culturales representaban a grandes sectores de intelectuales en los años setenta, ¿cuál es hoy la posición de estos intelectuales “orgánicos”? ¿Qué nuevos espacios públicos ocupan? Feinmann pareciera concentrar su ejercicio crítico desde los aparatos de la industria cultural, periodismo político - Página 12 - o cultural La Maga - guiones fílmicos, industria cultural constituida como la nueva dominante de la instancia pública de reacomodamiento para numerosos intelectuales de aquella época setentista, en su experiencia histórica de fines de los años noventa.

\section{BIBLIOGRAFIA}

Altamirano, Carlos. "Montoneros". Punto de Vista 55 (1996): 1-9.

Beceyro, Raúl. "Fantasmas del pasado". Punto de Vista 55 (1996): 10-12.

Bourdieu, Pierre. Choses Dites. París: Les Editions de Minuit, 1987.

Castañeda, Jorge G. La utopía desarmada. México: Joaquín Mortiz-Planeta, 1993.

Castex, Mariano. El país del Minotauro. Buenos Aires: El Cid Dist., 1983.

Feinmann, José Pablo. La astucia de la razón. Buenos Aires: Alfaguara Ediciones, 1990. Firpo, Norberto. Cuerpo a tierra. Buenos Aires: Galerna, 1983.

Fraser, Nancy. "Rethinking the Public Sphere: A Contribution to the Critique of Actually Existing Democracy". Habermas and the Public Sphere. Craig Calhoun, ed. Cambridge, MA y Londres: The MIT Press, 1992. 109-137.

Grandis, Rita de. Polémica y estrategias narrativas en América Latina. Rosario: Beatriz Viterbo, 1993. 
Hodges, Donald C. "The Argentine Left since Perón". The Latin American Left From the Fall of Allende to Perestroiska. Barry Carr y Steve Ellner, eds. Bolder: Westview Press Inc., 1993. 155-170.

Maristany, José. "Censura cultural y discurso literario: la estrategia de Respiración artificial'. Cahiers du Gral (Université de Montréal, 1994).

Medina, Enrique. Con el trapo en la boca. Buenos Aires: Galerna, 1983.

Piglia, Ricardo. Respiración artificial. Buenos Aires: Editorial Sudamericana, 1988.

Sarlo, Beatriz. "Una alucinación dispersa en agonía". Punto de vista, 21 (1984): 1-8.

Shumway, Nicolás. Ficciones de representación de la Argentina. Buenos Aires: Sudamericana, 1993.

Vidal, Hernán, ed. Fascismoyexperiencialiteraria: Reflexiones para una recanonización. Institute For the Study of Ideologies and Literature. Minneapolis: University of Minnesota, 1985.

Viñas, David. Cuerpo a cuerpo. México: Siglo Veintiuno Editores, 1979.

White, Lucie. "Subordination, Rhetorical Survival Skills, and Sunday Shoes: Notes on the Hearing of Mrs. G.”. Buffalo Law Review 38/1 (Winter 1990): 1-58. 